Proceedings

\title{
An Open Access Resource Portal for Arthropod Vectors and Agricultural Pathosystems: AgriVectors.org ${ }^{\dagger}$
}

\author{
Surya Saha ${ }^{1,2}$, , W. Rodney Cooper ${ }^{3}$, The AgriVectors Consortium, Wayne B. Hunter ${ }^{4}$ and Lukas A. Mueller ${ }^{1}$ \\ 1 Boyce Thompson Institute, Ithaca, NY 14853, USA; suryasaha@cornell.edu; (S.S.); lam87@cornell.edu \\ (L.A.M.) \\ 2 Animal and Comparative Biomedical Sciences, University of Arizona, Tucson, AZ 85721, USA; \\ suryasaha@arizona.edu \\ 3 USDA, ARS, Temperate Tree Fruit and Vegetable Research Unit, Wapato, WA 98951, USA; Rod- \\ ney.cooper@usda.gov \\ 4 USDA, ARS, U.S. Horticultural Research Laboratory, Ft. Pierce, FL 34945, USA; wayne.hunter@usda.gov \\ * Correspondence: suryasaha@cornell.edu \\ + Presented at the 1st International Electronic Conference on Entomology (IECE 2021), 1-15 July 2021; \\ Available online: https://iece.sciforum.net/.
}

Citation: Saha, S.; Cooper, W.R.; Hunter, W.B; Mueller, L.A. An Open Access Resource Portal for Arthropod Vectors and Agricultural Pathosystems: AgriVectors.org, in Proceedings of the 1st International Electronic Conference on Entomology, 1-15 July 2021, MDPI: Basel, Switzerland, doi:10.3390/IECE-10576

Published: 2 July 2021

Publisher's Note: MDPI stays neutral with regard to jurisdictional claims in published maps and institutional affiliations.

Copyright: (C) 2021 by the authors. Submitted for possible open access publication under the terms and conditions of the Creative Commons Attribution (CC BY) license (http://creativecommons.org/licenses /by/4.0/).

\begin{abstract}
Arthropod vectors of plant pathogens cause enormous economic losses and are a fundamental challenge for sustainable food production. To develop more effective control of plant pathogens and pests, data pertaining to disease systems need to be consolidated, made accessible, searchable and amenable to data mining. The AgriVectors ${ }^{\mathrm{TM}}$ platform is an open access and comprehensive resource for growers, researchers and industry who are working on insect-vectored plant pathogens. The portal connects established public repositories with 'pathosystem-specific' data repositories. Current resources include the Asian citrus psyllid, the potato psyllid and the bacterial pathogens they transmit to citrus and Solanaceous plants. Expansion to include resources for other important Hemipteran vectors (whiteflies, leafhoppers, planthoppers, scale, mealybugs etc.), thrips. and mites is planned. There is also the capacity to set up private and protected databases for protected access as needed. Linking visual data with gene expression profiles using 3D microCT technology will expand the understanding and use of diverse and complex data. The AgriVectors portal will extend this model beyond gene-centric omics-data to the broader Systems Biology Pathosystem-wide information, with integrated pest management, behavior, plant health, soil health and climate data so that users can rapidly incorporate phenotyping information from greenhouse and field trials. This will establish a foundation for more effective identification and development of solutions for the control of plant diseases. AgriVectors portal creates a user-friendly platform that fosters interdisciplinary collaborations among researchers of diverse plant pathosystems, to simplify data sharing, ideas, and technologies to develop solutions for managing plant diseases.
\end{abstract}

Keywords: arthropod; database; vector; pathogen; psyllid; open access; plant disease

\section{Introduction}

Arthropod vectors of pathogens cause enormous economic losses and are a fundamental challenge for sustainable food production, yet agricultural pathosystems remain an under-served area of research. Presented here is a system that collects and organizes data for improved accessibility and functional analysis. Interactive data analyses can shorten the time it takes to identify and develop solutions to complex pathosystems. Thus, to develop more effective control of plant pathogens and pests, data pertaining to a disease system needs to be consolidated, made accessible, searchable and amenable to data mining. Our goal is to develop a publicly-available bioinformatics database under the AgriVectors platform that includes multiple arthropod vectors, plant pathogens and host 
plants to enable rapid development of cross-vector targets and control technologies. The initial focus areas of the AgriVectors portal are two important, related Hemipteran vectors - the Asian citrus psyllid (Diaphorina citri) and potato/tomato psyllid (Bactericera cockerelli) - with the goal to foster collaborations between potato and citrus researchers and enable the researchers to adapt tools and technologies developed for Candidatus Liberibacter asiaticus (CLas) and the citrus psyllid vector, to target Candidatus L. solanacearum (CLso) and the potato psyllid vector.

Diaphorina citri is the vector of Ca. Liberibacter asiaticus (CLas), the plant-infecting bacterium that causes Huanglongbing (HLB), (aka. citrus greening disease). CLas is the most important pathogen of citrus globally, yet there are no commercially available methods to directly control the pathogen. Therefore, HLB management is heavily based on management practices to reduce populations of the psyllid vector. To provide a better understanding of the insect's biology and the interactions among CLas, the psyllid vector, and host plants, we designed citrusgreening.org [1]. This is a precursor to the larger AgriVectors portal. Citrusgreening.org is a web portal with information for citrus growers, plant geneticists, entomologists, vector biologists and plant pathologists within the international citrus greening research community. This portal provides resources for organisms associated with the Huanglongbing pathosystem including citrus psyllid, psyllid endosymbionts, CLas pathogen, tree endophytes, and host plants. The psyllid Expression Atlas contains proteomics and RNAseq data across multiple citrus hosts and a variety of physiological infection states and is available to identify candidate genes associated with pathogen acquisition and transmission [2-5].

Bactericera cockerelli is a vector of Ca. L. solanacearum (CLso), the pathogen that causes zebra chip disease of potato, and foliar dieback in other Solanaceous crops. The psyllid completes development on a wide range of non-crop host plants within the Solanaceae and Convolvulaceae, and many of these host plants are also reservoirs for CLso. Potato psyllid populations contain at least four haplotypes that differ with respect to host plant preference, presence of specific bacterial endosymbionts, and other biological traits [6-8]. CLso also occurs as several distinct haplotypes, with two haplotypes - haplotype A and haplotype B - of primary concern in the United States [9]. Liberibacter haplotype B appears more virulent than haplotype $\mathrm{A}$ in potato and tomato [10,11]. CLso is also transmitted to species of Convolvulaceae by Bactericera maculipennis [12], and to carrot and celery by several psyllid vectors in Europe [13]. Genomic and transcriptomic databases, including data on feeding behavior, pathogen transmission, and endosymbionts are available for various potato psyllid and CLso haplotypes, but consolidated platforms like citrusgreeing.org for analyses of these large datasets have been lacking for this pathosystem [4].

The goal of the AgriVectors working group is to consolidate large datasets from many different plant pathosystems and to provide a portal with online web tools to allow researchers to analyze datasets and compare results across pathosystems. Contemporary research is progressing toward the ability to use highly-specific gene-based therapies to target insects and pathogens in crops [14-18]. Indeed, the citrusgreening.org web portal has already helped researchers develop several RNAi biopesticides which have been patented for control of D. citri (US patent 10,344,291_B2), and several patented antisense oligos (US patent 11,001,842 B2) that target and reduce CLas, CLso, and insect endosymbionts $[15,19,20]$. Expansion of the AgriVectors portal to include information and datasets on other arthropod vectors of pathogens will increase resources for many other plant pathosystems. Access to these data will encourage multi crop and multidisciplinary collaborations, allowing researchers to adapt novel technologies developed for citrus and psyllid vectors to target other insect vectors and pathogens that cause disease in other cropping systems including row crops, fruits, ornamentals, and stored grains. The open access and collaborations from each successful project under the umbrella of AgriVectors improves the skills of researchers, while fostering broader collaborations, and coordinates 
resource convergence under a fast-track strategy for producing multiple solutions to a broad range of insect vectors and plant pathogens.

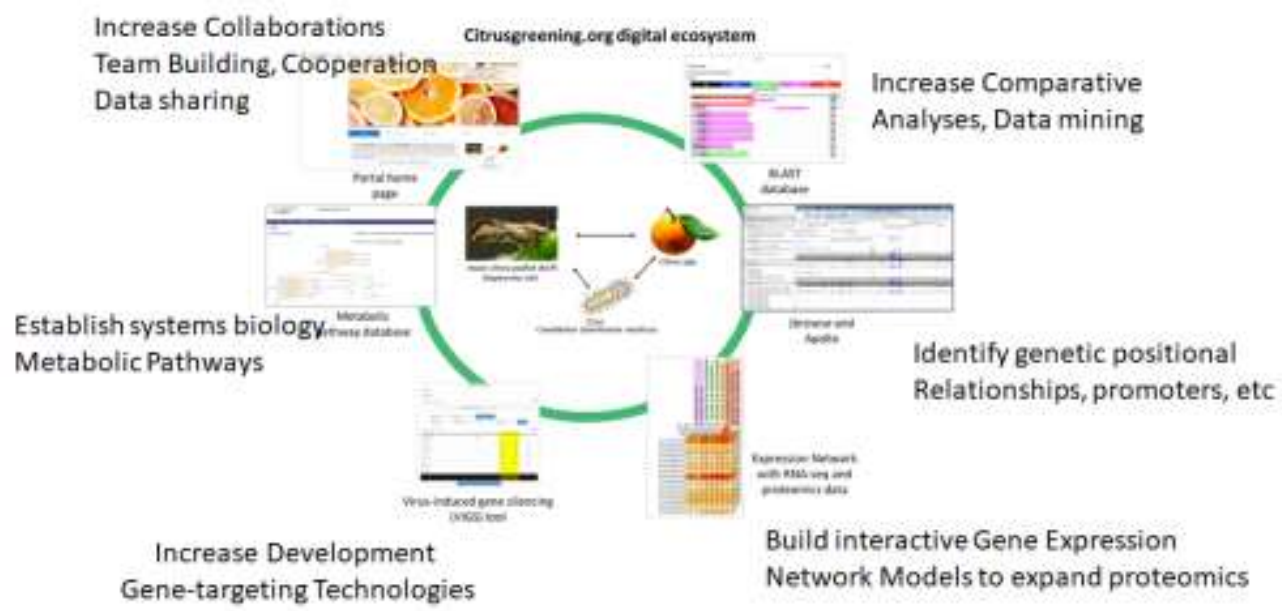

Figure 1. The Citrusgreening digital ecosystem representing a complex pathosystem.

\section{Methods}

A Systems Biology portal based on the Citrusgreening.org community resource that was successfully developed as a model of the Citrus Pathogen systems biology of tritrophic disease interactions.

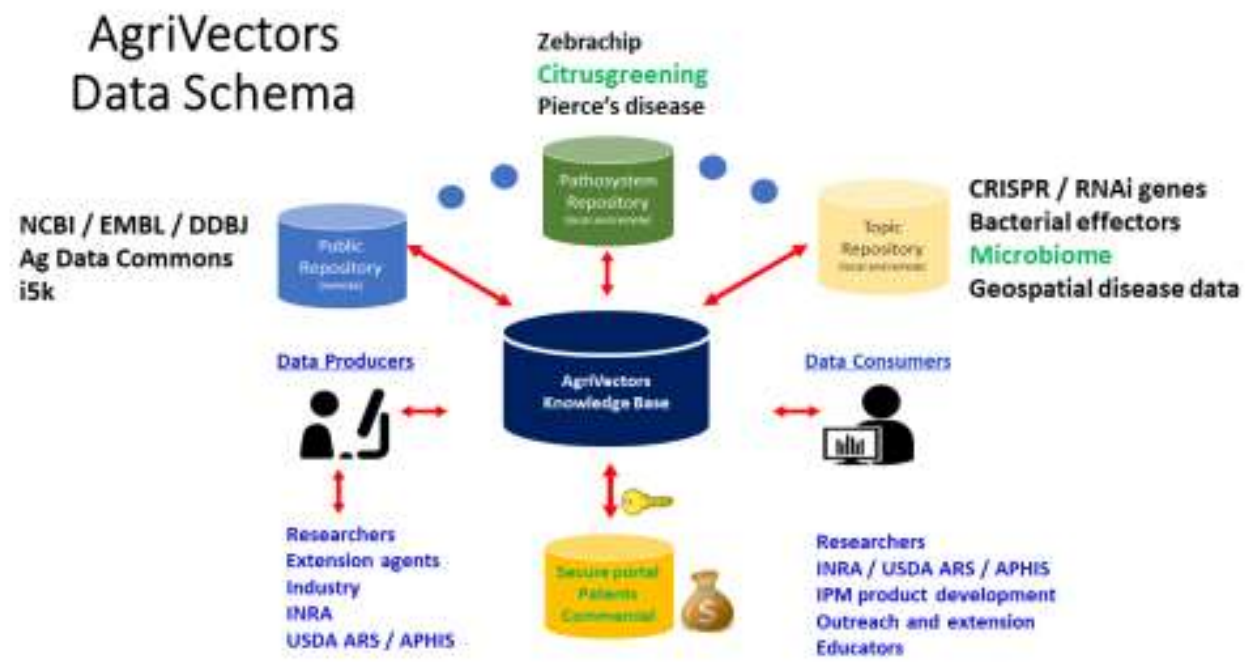

Figure 2. The AgriVectors digital ecosystem with linkages to various data stores including public data and private data sources in addition to pathosystem-specific repositories.

\subsection{Database Implementation}

We use a Chado relational schema [21] with custom extensions in the PostgreSQL relational database system. The current data model consists of a user-facing view code, server side control and data modules with a relational database backend. A number of the site's core functionality is based on the open source generic model organism database (GMOD) tools [22], such as Chado, Bio::Chado::Schema, Apollo and Jbrowse. The Blast services are provided by the NCBI BLAST+ suite. Flat files are used for storage purposes to complement the relational database as required, e.g. for storing large sequence data, metabolomics data and electrical penetration (EPG) graphs. All software source code and development logs are publicly viewable $[23,24]$. 


\subsection{Expression Atlas and Pathway Databases}

The Expression Atlas contains high-resolution expression data from proteomics and RNA-Seq datasets based on the Diaphorina citri v1.0 and v2.0 genome references. Gene expression values were obtained after mapping with HISAT2 [25] to the reference genome assembly. Expression counts were obtained using Stringtie and quantified using the transcripts per million reads (TPM) metric. Pathway/Genome Databases (PGDBs) were created using Pathway Tools [26] for pathway visualization and analysis. An organism specific pathway database was constructed using annotated proteins and curated pathways in MetaCyc [27].

\section{Results and Discussion}

The AgriVectors ${ }^{\mathrm{TM}}$ platform is an open access, comprehensive resource for growers, researchers and industry who are working on plant pathogens and pathosystems that are spread by arthropod vectors. The portal connects established public repositories with 'pathosystem-specific' data repositories. Current resources include the Asian citrus psyllid, the potato psyllid and the bacterial pathogens they transmit to citrus and Solanaceous plants. Expansion to include other important hemipteran vectors (whiteflies, leafhoppers, planthoppers, scale, mealybugs etc.), along with thrips and mites is planned. There is also a capacity to set up private and protected databases for restricted access as needed. The portal is based on the Citrusgreening.org community resource that was developed as a model for systems biology of tritrophic disease complexes. This open source platform has led to many productive collaborations across multiple disciplines. The importance of shared, consolidated, datasets will be critical to develop rapid solutions to the supervectors $[28,29]$ and crop pandemics of the future [30].

High-quality genomes, gene predictions and comprehensive genome independent transcriptomes have been added to the AgriVectors database and are available to the community with user-friendly tools for multi-omics analysis, enabling users to 'build-by-association' to accelerate their own success. Metabolic pathway databases provide organism specific pathways that can be used to mine metabolomic, transcriptomic, and proteomic results to identify pathways and regulatory mechanisms involved in disease response. All tools like the Apollo gene curation tool, JBrowse genome browser, Biocyc metabolic pathway databases, Blast sequence analysis tools connect to a central database containing gene models for plant host, insect vector, their endosymbionts and multiple Liberibacter pathogens. The portal includes user-friendly manual curation tools to allow the research community to continuously improve this knowledge base as more experimental research is published. Toxicology, physiology, and developmental biology along with behavior studies like electrical penetration graph data [31], from various psyllid populations, is available and will be expanded to other genera. The genome and gene predictions enable the research community to identify specific homologs with psyllid genes that were shown to be effective suppression targets by previously published studies [32]. Furthermore, multiple genomic libraries enable the validation and identifications of new promoters, and gene functions that may have gone undiscovered in other systems.

A major goal of the AgriVectors working group is to establish interconnectivity with public repositories such as the i5k workspace, NCBI and EMBL, as well as independent research communities (aphidbase, vectorbase, etc.) to integrate additional resources. This will be implemented using application programming interfaces (APIs) and web services to aggregate information in the portal for the user. The portal handles user-supplied multi-omics data from metabolomics, transcriptomics and proteomics experiments. Nonomics data like images, electrical penetration graphs, disease trials, life tables, and safety assays can also be easily integrated. Transcriptomic data is one of the most widely used resources for functional genomics and will be a focus for developing cross-species tools that improve comparative analyses and gene/protein identification. Pathosystem-specific databases like Citrusgreening.org will be set up for research communities as required, 
with an ever-expanding capacity to search across, between, and among these data. This interconnectivity among public repositories and the convenient availability of web-based tools for data analysis will enable researchers to compare datasets across multiple pathosystems and to adapt novel technologies and products to target new pathogens or vectors [3,29,33-35].

\section{Conclusions}

The AgriVectors portal has demonstrated its utility and value to research teams working to develop rapid solutions to complex pathosystems, producing biopesticides, and other gene-targeting products within a few years [36-38]. We plan to expand to diseases of fruit crops including $\mathrm{x}$-disease of stone fruits caused by $\mathrm{Ca}$. Phytoplasma pruni [39], Pierces disease caused by Xylella fastidiosa [40] and other phytoplasma caused crop diseases [41], and various viral pathogens [28,29]. The AgriVectors portal will extend this model beyond gene-centric omics-data to the broader Systems Biology Pathosystem-wide information, with integrated pest management, behavior, plant health, soil health and climate data so that users can incorporate rapid phenotyping information from research trials. Collectively, integrating these diverse resources into a single portal will build a stronger foundation to quickly develop solutions to control plant diseases for the community. We envision the AgriVectors portal serving as a virtual lounge for researchers of insect vectored plant pathogens where they can form collaborations across disciplines and cropping systems, share data, and expand the use of novel tools for the study and control of plant pathogens and their arthropod vectors across pathosystems.

Author Contributions: Conceptualization, S.S., L.M., R.C. and W.H.; methodology, S.S. and L.M.; software, S.S. and L.M.; resources, S.S, R.C. and W.H.; writing-original draft preparation, S.S.; writing -review and editing, R.C. and W.H..; visualization, S.S.; project administration, S.S and L.M..; funding acquisition, S.S and R.C. All authors have read and agreed to the published version of the manuscript.

Funding: Partial funding was provided by the ARS/State Potato Partnership Program.

Data Availability Statement: All resources are available at agrivectors.org.

Conflicts of Interest: The authors declare no conflict of interest. The funders had no role in the design of the study; in the collection, analyses, or interpretation of data; in the writing of the manuscript, or in the decision to publish the results.

\section{References}

1. Flores-Gonzalez, M.; Hosmani, P.S.; Fernandez-Pozo, N.; Mann, M.; Humann, J.L.; Main, D.; Heck, M.; Brown, S.J.; Mueller, L.A.; Saha, S. Citrusgreening.org: An Open Access and Integrated Systems Biology Portal for the Huanglongbing (HLB) Disease Complex. bioRxiv 2019, 868364 .

2. El-Desouky, A.; Shatters, R.G., Jr; Heck, M. Huanglongbing Pathogens: Acquisition, Transmission and Vector Interactions. Asian citrus psyllid: biology, ecology and management of the Huanglongbing vector 2020, 113-139.

3. Kruse, A.; Fleites, L.A.; Heck, M. Lessons from One Fastidious Bacterium to Another: What Can We Learn about Species from. Insects 2019, 10, doi:10.3390/insects10090300.

4. Tang, X.-T.; Longnecker, M.; Tamborindeguy, C. Acquisition and Transmission of Two “Candidatus Liberibacter Solanacearum" Haplotypes by the Tomato Psyllid Bactericera Cockerelli. Sci. Rep. 2020, 10, 14000, doi:10.1038/s41598-020-70795-4.

5. Ramsey, J.S.; Johnson, R.S.; Hoki, J.S.; Kruse, A.; Mahoney, J.; Hilf, M.E.; Hunter, W.B.; Hall, D.G.; Schroeder, F.C.; MacCoss, M.J.; et al. Metabolic Interplay between the Asian Citrus Psyllid and Its Profftella Symbiont: An Achilles' Heel of the Citrus Greening Insect Vector. PLoS One 2015, 10, e0140826, doi:10.1371/journal.pone.0140826.

6. Cooper, A.M.; Silver, K.; Zhang, J.; Park, Y.; Zhu, K.Y. Molecular Mechanisms Influencing Efficiency of RNA Interference in Insects. Pest Manag. Sci. 2019, 75, 18-28, doi:10.1002/ps.5126.

7. Swisher, K.D.; Munyaneza, J.E.; Crosslin, J.M. High Resolution Melting Analysis of the Cytochrome Oxidase I Gene Identifies Three Haplotypes of the Potato Psyllid in the United States. Environmental Entomology 2012, 41, 1019-1028.

8. Cooper, W.R.; Swisher, K.D.; Garczynski, S.F.; Mustafa, T.; Munyaneza, J.E.; Horton, D.R. Wolbachia Infection Differs Among Divergent Mitochondrial Haplotypes of Bactericera Cockerelli (Hemiptera: Triozidae). Annals of the Entomological Society of America 2015, 108, 137-145. 
9. Lin, H.; Islam, M.S.; Bai, Y.; Wen, A.; Lan, S.; Gudmestad, N.C.; Civerolo, E.L. Genetic Diversity of “Cadidatus Liberibacter Solanacearum" Strains in the United States and Mexico Revealed by Simple Sequence Repeat Markers. European Journal of Plant Pathology 2012, 132, 297-308.

10. Swisher Grimm, K.D.; Garczynski, S.F. Identification of a New Haplotype of "Candidatus Liberibacter Solanacearum" in Solanum Tuberosum. Plant Dis. 2019, 103, 468-474, doi:10.1094/PDIS-06-18-0937-RE.

11. Harrison, K.; Tamborindeguy, C.; Scheuring, D.C.; Herrera, A.M.; Silva, A.; Badillo-Vargas, I.E.; Creighton Miller, J.; Levy, J.G. Differences in Zebra Chip Severity between "Candidatus Liberibacter Solanacearum" Haplotypes in Texas. American Journal of Potato Research 2019, 96, 86-93.

12. Borges, K.M.; Cooper, W.R.; Garczynski, S.F.; Thinakaran, J.; Jensen, A.S.; Horton, D.R.; Munyaneza, J.E.; Cueva, I.; Barcenas, N.M. “Candidatus Liberibacter Solanacearum” Associated With the Psyllid, Bactericera Maculipennis (Hemiptera: Triozidae). Environ. Entomol. 2017, 46, 210-216, doi:10.1093/ee/nvw174.

13. Munyaneza, J.E.; Fisher, T.W.; Sengoda, V.G.; Garczynski, S.F.; Nissinen, A.; Lemmetty, A. First Report of “Candidatus Liberibacter Solanacearum" Associated with Psyllid-Affected Carrots in Europe. Plant Dis. 2010, 94, 639, doi:10.1094/PDIS-94-50639A.

14. Das, P.R.; Sherif, S.M. Application of Exogenous dsRNAs-Induced RNAi in Agriculture: Challenges and Triumphs. Front. Plant Sci. 2020, 11, 946, doi:10.3389/fpls.2020.00946.

15. Hunter, W.B.; Clarke, S.-K.V.; Sandoval Mojica, A.F.; Paris, T.M.; Miles, G.; Metz, J.L.; Holland, C.S.; McCollum, G.; Qureshi, J.A.; Tomich, J.M.; et al. Advances in RNA Suppression of the Asian Citrus Psyllid Vector and Bacteria (huanglongbing Pathosystem). Asian citrus psyllid: biology, ecology and management of the Huanglongbing vector 2020, $258-283$.

16. Andrade, E.C. de; de Andrade, E.C.; Hunter, W.B. RNA Interference - Natural Gene-Based Technology for Highly Specific Pest Control (HiSPeC). RNA Interference 2016.

17. Rodrigues, T.B.; Figueira, A. Management of Insect Pest by RNAi - A New Tool for Crop Protection. RNA Interference 2016.

18. Wintermantel, W.M.; Hladky, L.L.; Cortez, A.A. Genome Sequence, Host Range, and Whitefly Transmission of the Torradovirus Tomato Necrotic Dwarf Virus. Acta Horticulturae 2018, 295-302.

19. Sandoval-Mojica, A.F.; Altman, S.; Hunter, W.B.; Pelz-Stelinski, K.S. Peptide Conjugated Morpholinos for Management of the Huanglongbing Pathosystem. Pest Manag. Sci. 2020, 76, 3217-3224, doi:10.1002/ps.5877.

20. Sandoval-Mojica, A.F.; Hunter, W.B.; Aishwarya, V.; Bonilla, S.; Pelz-Stelinski, K.S. Antibacterial FANA Oligonucleotides as a Novel Approach for Managing the Huanglongbing Pathosystem. Sci. Rep. 2021, 11, 2760, doi:10.1038/s41598-021-82425-8.

21. Mungall, C.J.; Emmert, D.B.; FlyBase Consortium A Chado Case Study: An Ontology-Based Modular Schema for Representing Genome-Associated Biological Information. Bioinformatics 2007, 23, i337-46, doi:10.1093/bioinformatics/btm189.

22. GMOD Available online: http://gmod.org (accessed on 13 June 2021).

23. solgenomics Solgenomics/sgn Available online: https://github.com/solgenomics/sgn (accessed on 13 June 2021).

24. solgenomics Solgenomics/agrivectors Available online: https://github.com/solgenomics/agrivectors (accessed on 13 June 2021).

25. Kim, D.; Paggi, J.M.; Park, C.; Bennett, C.; Salzberg, S.L. Graph-Based Genome Alignment and Genotyping with HISAT2 and HISAT-Genotype. Nat. Biotechnol. 2019, 37, 907-915, doi:10.1038/s41587-019-0201-4.

26. Karp, P.D.; Midford, P.E.; Billington, R.; Kothari, A.; Krummenacker, M.; Latendresse, M.; Ong, W.K.; Subhraveti, P.; Caspi, R.; Fulcher, C.; et al. Pathway Tools Version 23.0 Update: Software for Pathway/genome Informatics and Systems Biology. Briefings in Bioinformatics 2021, 22, 109-126.

27. Caspi, R.; Billington, R.; Fulcher, C.A.; Keseler, I.M.; Kothari, A.; Krummenacker, M.; Latendresse, M.; Midford, P.E.; Ong, Q.; Ong, W.K.; et al. The MetaCyc Database of Metabolic Pathways and Enzymes. Nucleic Acids Res. 2018, 46, D633-D639, doi:10.1093/nar/gkx935.

28. Gilbertson, R.L.; Batuman, O.; Webster, C.G.; Adkins, S. Role of the Insect Supervectors Bemisia Tabaci and Frankliniella Occidentalis in the Emergence and Global Spread of Plant Viruses. Annu Rev Virol 2015, 2, 67-93, doi:10.1146/annurev-virology031413-085410.

29. Legg, J.; Somado, E.A.; Barker, I.; Beach, L.; Ceballos, H.; Cuellar, W.; Elkhoury, W.; Gerling, D.; Helsen, J.; Hershey, C.; et al. A Global Alliance Declaring War on Cassava Viruses in Africa. Food Security 2014, 6, 231-248.

30. He, S.; Creasey Krainer, K.M. Pandemics of People and Plants: Which Is the Greater Threat to Food Security? Mol. Plant 2020, 13, 933-934, doi:10.1016/j.molp.2020.06.007.

31. Ebert, T.A. The Probing Behavior Component of Disease Transmission in Insect-Transmitted Bacterial Plant Pathogens. Insects 2019, 10, doi:10.3390/insects10070212.

32. Chung, S.H.; Feng, H.; Jander, G. Engineering Pest Tolerance through Plant-Mediated RNA Interference. Curr. Opin. Plant Biol. 2021, 60, 102029, doi:10.1016/j.pbi.2021.102029.

33. Landa, B.B.; Castillo, A.I.; Giampetruzzi, A.; Kahn, A.; Román-Écija, M.; Velasco-Amo, M.P.; Navas-Cortés, J.A.; Marco-Noales, E.; Barbé, S.; Moralejo, E.; et al. Emergence of a Plant Pathogen in Europe Associated with Multiple Intercontinental Introductions. Appl. Environ. Microbiol. 2020, 86, doi:10.1128/AEM.01521-19.

34. Fiallo-Olivé, E.; Pan, L.-L.; Liu, S.-S.; Navas-Castillo, J. Transmission of Begomoviruses and Other Whitefly-Borne Viruses: Dependence on the Vector Species. Phytopathology 2020, 110, 10-17, doi:10.1094/PHYTO-07-19-0273-FI.

35. Leonard, S.P.; Powell, J.E.; Perutka, J.; Geng, P.; Heckmann, L.C.; Horak, R.D.; Davies, B.W.; Ellington, A.D.; Barrick, J.E.; Moran, N.A. Engineered Symbionts Activate Honey Bee Immunity and Limit Pathogens. Science 2020, 367, 573-576, doi:10.1126/science.aax9039. 
36. Hunter, W.B.; Gonzalez, M.T.; Andrade, E.C. Double stranded RNA compositions for reducing Asian citrus psyllid infestation and methods of use. U.S. Patent Number 10,344,291 B2.

37. Pelz-Stelinski, K.S.; Hunter, W.B. Peptide phosphorodiamidate morpholino oligo-mers plant delivery to reduce pathogens \& insect pests. U.S. Patent Number US 11,001,842 B2.

38. Hunter, W.B.; Cooper, W.R.; Sandoval-Mojica, A.F.; McCollum, G.; Aishwarya, V.; Pelz-Stelinski, K.S. Improving sup-pression of hemipteran vectors and bacterial pathogens of citrus and Solanaceous plants: Advances in antisense oligonu-cleotides (FANA). Front. Agron. doi: 10.3389/fagro.2021.675247.

39. Huang, W.; Reyes-Caldas, P.; Mann, M.; Seifbarghi, S.; Kahn, A.; Almeida, R.P.P.; Béven, L.; Heck, M.; Hogenhout, S.A.; Coaker, G. Bacterial Vector-Borne Plant Diseases: Unanswered Questions and Future Directions. Mol. Plant 2020, 13, 1379-1393, doi:10.1016/j.molp.2020.08.010.

40. Schneider, K.; van der Werf, W.; Cendoya, M.; Mourits, M.; Navas-Cortés, J.A.; Vicent, A.; Oude Lansink, A. Impact of Subspecies in European Olives. Proc. Natl. Acad. Sci. U. S. A. 2020, 117, 9250-9259, doi:10.1073/pnas.1912206117.

41. Ebadi, N.; Najafipour, G.; Faghihi, M.M.; Ayazpour, K.; Salehi, M. Interaction between "Candidatus Phytoplasma Australasiae" and Tomato Yellow Leaf Curl Virus in Tomato Plants. Eur. J. Plant Pathol. 2020, 158, 733-744, doi:10.1007/s10658-020-02114-6. 